\title{
Fine Motor Skill Proficiency in Obese Children
}

Gaul, D. and Issartel, J.

Multisensory Motor Learning Lab., Dublin City University, Dublin, Ireland

Introduction:

- Motor skill proficiency has been shown to be a key predictor of children's engagement and enjoyment inregular physical activity.

- Recent evidence suggests that obese children have increased difficulties in planning, initiation and control of motor skills compared to their normal weighted peers (D'Hondt et al 2009, Gentier et al 2013).

\section{Objectives:}

- To examine the influence of mass and gender on fine motor skill proficiency in Irish school children.

- To investigate if obesity influences motor skill proficiency beyond mechanical constraints associated with excess mass.

\section{Methodology:}

- 8-10 year old children $(\mathrm{N}=45)$ were divided into Obese (OB) and Normal Weight (NW) based on IOTF cut-offs for BMI.

- Children were assessed using the Fine Motor Composite of the Bruininks Oseretsky Test of Motor Proficiency 2nd Edition (BOT-2).

- Children's raw scores were standardized based on normative data.

- Informed consent was obtained from the parents of all children.

\section{Results:}

- The OB group scored significantly lower $(p<0.05)$ for Manual Coordination ( 45.70 vs. 51.17 ) and for the Total Composite Score (46.13 vs. 52.04 ) than the NW group.

- On average the OB group were found to fall below average ( $37^{\text {th }}$ Percentile) compared to the NW group ( $58^{\text {th }}$ Percentile).

- There was no significant difference for Fine Manual Control.

- There were no significant gender differences found.
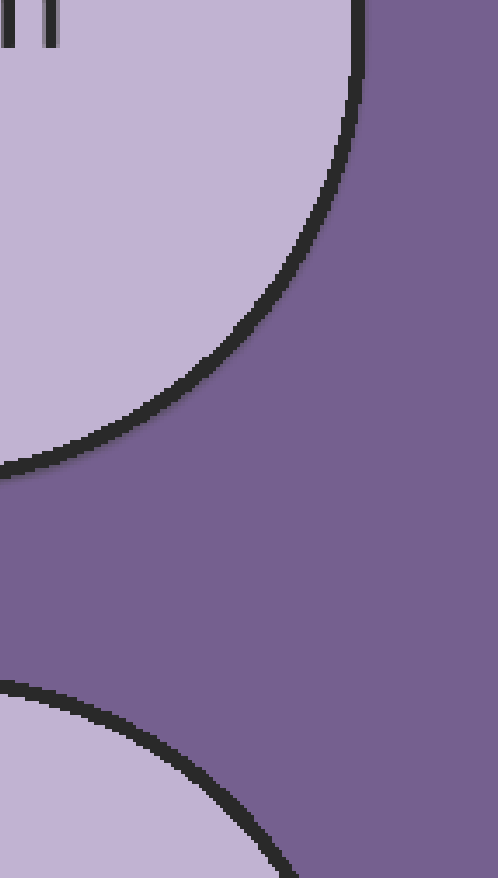

er

is
\section{n}

Conclusion:

\section{Conclusion:}

As body mass has limited influence in the performance of fine motor skills (writing, cutting, etc..), these findings suggest the existence of a deficit in how obese children integrate and process sensory information compared to their normal weighted peers. If this is the case, it could impede their performance of everyday activities as well as affect their willingness to engage in physical activity. Further research is required to understand the extent of these difficulties and whether or not they persist throughout childhood.

\section{References:}

- D'Hondt et al 2009, Applied Physical Activity Quarterly (26)1

- Gentier et al 2013, Research in Developmental Disabilities (34)11

\section{Participants Demographics:}

\begin{tabular}{|c|c|c|c|c|c|}
\hline & $\mathbf{N}$ & Male & Female & Age( $\pm S D)$ & $\mathrm{BMI}( \pm \mathrm{SD})$ \\
\hline $\begin{array}{l}\text { Normal } \\
\text { Weight }\end{array}$ & 23 & 11 & 12 & $9.1 \pm 1.83$ & $16.41 \pm 2.06$ \\
\hline Obese & 23 & 11 & 12 & $9.1 \pm 1.75$ & $25.93 \pm 3.62$ \\
\hline
\end{tabular}

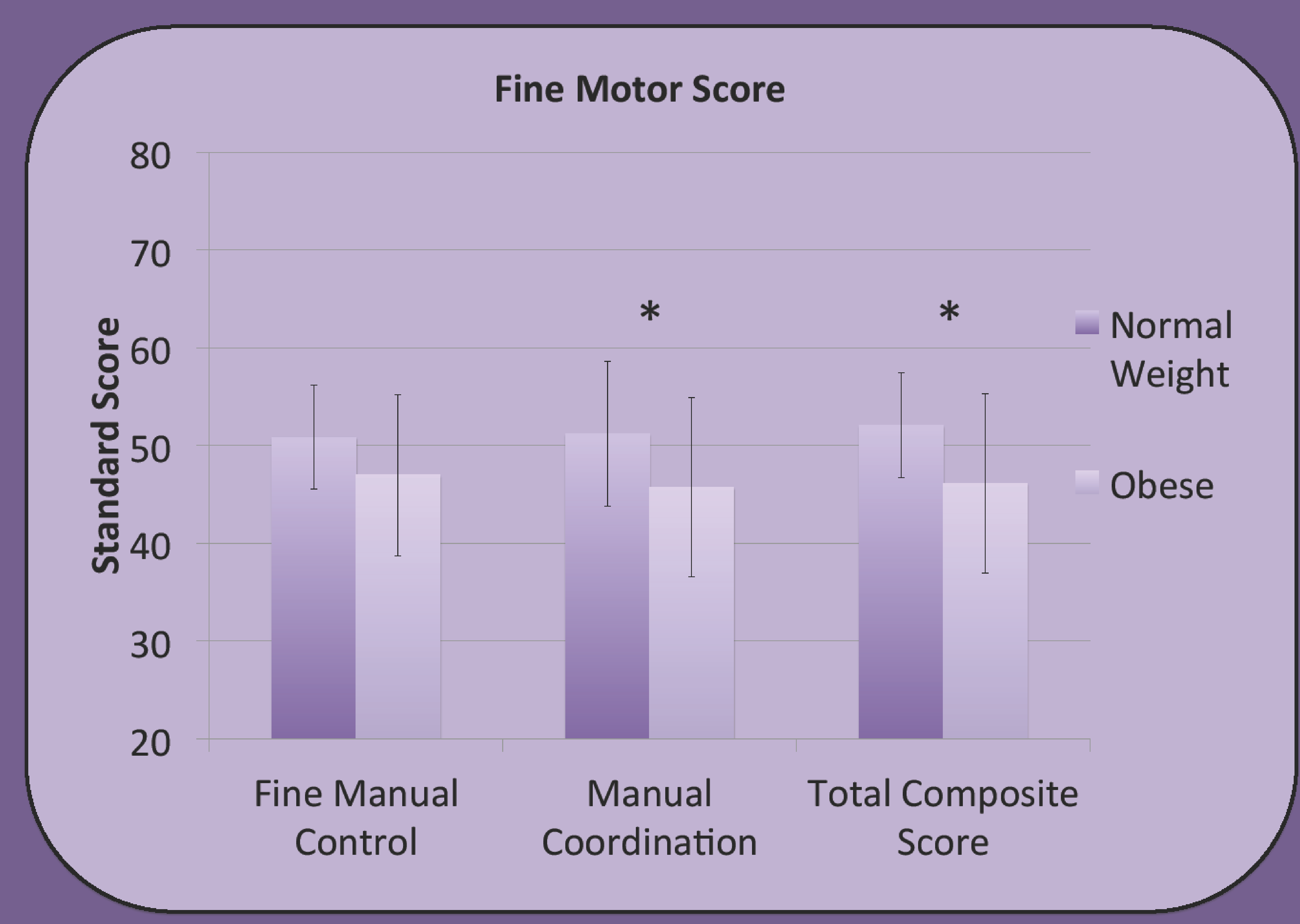

